
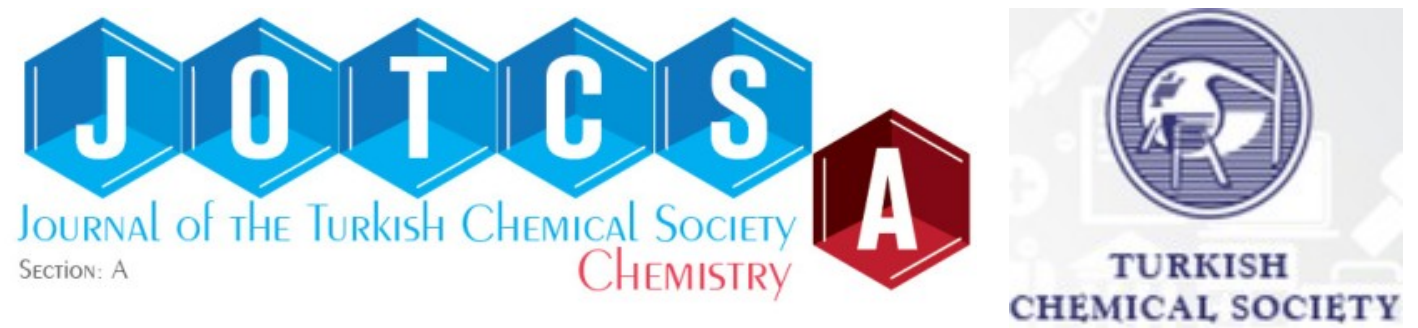

\title{
Production of Rosmarinic Acid Nanoparticles, and Investigation of Anti- Oxidation Effects on Salmon Fish Meat
}

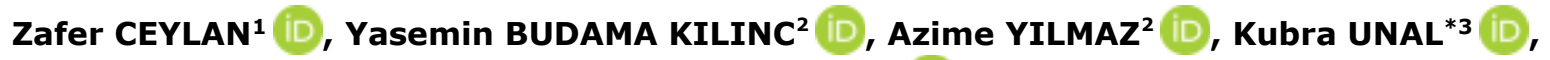 \\ Burak OZDEMIR ${ }^{4}$
${ }^{1}$ Van Yüzüncü Yil University, Faculty of Tourism, Department of Gastronomy and Culinary Arts, Tuşba, Van, Turkey
${ }^{2}$ Yildiz Technical University, Department of Bioengineering, Istanbul, Turkey
${ }^{3}$ Selcuk University, Department of Food Engineering, Konya, Turkey
${ }^{4}$ Yildiz Technical University, Department of Bioengineering, Istanbul, Turkey

\begin{abstract}
In this study, an anti-oxidant nanoformulation to prevent the oxidation of salmon was developed using rosmarinic acid (RA). Minced salmon samples (MSs) were treated with $8.10^{-3} \mathrm{~g}$ (RAT1) and $16.10^{-3} \mathrm{~g}$ (RAT2) RA-loaded nanoparticles for $100 \mathrm{~g}$ MS rosmarinic acid, separately. The thiobarbituric acid (TBA) values of control (C), RAT1, and RAT2 samples stored at $4{ }^{\circ} \mathrm{C}$ were found as $2.995,1.350$, and $0.994 \mathrm{mg} \mathrm{MDA} / \mathrm{kg}$; respectively, after 9 days. While the initial free fatty acid (FFA) value of $\mathrm{C}$ samples was $2.011 \%$, RAT1 and RAT2 were found as $2.765 \%$ and $2.494 \%$, respectively. The 2,2,diphenylpicrylhydrazyl (DPPH) values of MSs treated with RAT1 and RAT2 were observed to be higher than that of C samples. C samples were evaluated as unfit for human consumption on the 5th day of the storage, it was revealed that but the sensory scores of MSs treated with RAT1 and RAT2 were still acceptable for human consumption.
\end{abstract}

Keywords: Nanotechnology application, nanoparticle, oxidation, rosmarinic acid, salmon quality.

Submitted: November 15, 2021. Accepted: February 03, 2022.

Cite this: Ceylan Z, Budama Kilinc Y, Yilmaz A, Unal K, Ozdemir B. Production of Rosmarinic Acid Nanoparticles, and Investigation of Anti-Oxidation Effects on Salmon Fish Meat. JOTCSA. 2022;9(2):31120.

DOI: https://doi.org/10.18596/jotcsa.1022787.

*Corresponding author. E-mail: ulusoy kubra@hotmail.com, tel: +903322232936.

\section{INTRODUCTION}

Well-balanced nutrition is a very crucial issue for consumers. In this respect, fish is a unique essential nutrient source for human (1). However, as soon as fish samples are caught, they must be protected by using appropriate food preservation methods. Therefore, different conventional food preservation methods are already used to delay the rapid deterioration in fish meat after harvesting. Ionizing irradiation treatment, packaging treatments, food additives, chilling, and freezing technology are widely used to limit the rapid deterioration in fish all over the world (2-4). Yet, food additives are applied to processed, lightly processed, or raw fish samples.
Furthermore, most of the food additives used in the fish processing industry are based on chemical origin. Since natural or organic-based food additives are highly expensive, they are not preferred by the fish processing industry. Also, some of the micro or macro natural-based food additives may have a lower antioxidant or bactericidal effect on fish fillets/samples. In this regard, cost-effective food preservation methods having stronger antimicrobial and antioxidant properties are currently being tried, particularly in the scientific area. For example, in the last decade, there has been a significant increase in microencapsulation methods. Moreover, food nanotechnology applications such as nanoencapsulation, nanocoating, nanoemulsions, 
nanoparticles, nanofibers recently take a great deal of attention in the food industry and scientific area. Ceylan, Sengor (5) revealed that nanofibers could be used as a nanocoating material for delaying the chemical deterioration in fish fillets. Özogul, Durmus (6) noted that nanoemulsions could be utilized to limit the rapid deterioration of fish samples. Osheba, Sorour (7) revealed that chitosan nanoparticle application successfully limited the rapid increase in chemical deteriorations parameters such as total volatile nitrogen, trimethylamine, and thiobarbituric acid in fish fingers. Ceylan, Sengor (8) reported that nano-thymol and the liquid smoke application delayed the rapid microbial spoilage in fish fillets during cold storage conditions. Also, the encapsulation of bio-based materials and functional ingredients are important and promising approaches for food nanotechnology applications. In this respect, encapsulations of nisin (9), rosehip seed oil (10), a-tocopherol (11), and zinc oxide (12) were successfully carried out, as can be seen from previous literature studies, as well. Additionally, nanomats that integrated with curcumin and nisin (13) or pomegranate seed oil (14), grape seed oilloaded nanofibers (15) and zein nanofibers (16) effectively improved the acceptability of fish meats during cold storage.

In this study, rosmarinic acid (RA), which is one of the polyphenolic substances contained in culinary herbs such as perilla, rosemary, sage, mint, and basil, was used. Therefore, there are many studies in which rosmarinic acid is provided with effective antioxidants and other quality properties. To the best of our knowledge, the number of antioxidant and lipid oxidation studies about RA-loaded nanoparticles of the salmon fish is limited. In this sense, the initial aim of the study was to encapsulate RA and characterize RA nanoparticles, such as average particle size and in vitro release profile. Also, the main aim of the present study was to investigate the potential antioxidative effect of RA-loaded nanoparticles on the salmon fish mince stored under $4^{\circ} \mathrm{C}$, and its effects on its shelf life.

\section{MATERIALS AND METHOD}

\section{Materials}

Salmon fish samples were obtained from an international supermarket in Konya, Turkey. The fish samples were immediately transferred to the food processing laboratory. RA ( $96 \%, M w=360.31$ $\mathrm{g} / \mathrm{mol})$, polycaprolactone (PCL) $(\mathrm{Mn}=80,000)$, and polyvinyl alcohol (PVA) ( $\mathrm{Mw}=31,000-50,000,87-$ $89 \%$ ) were purchased from Sigma-Aldrich (USA).

Treatment with Nanoparticles of Fish Samples The samples were grouped as control (C), RAT1 (8.10-3 g RA-loaded nanoparticle/ $100 \mathrm{~g}$ minced fish), and RAT2 (16.10-3 g RA-loaded nanoparticle/ $100 \mathrm{~g}$ of minced fish), as compared to RAT1). $100 \mathrm{~g}$ of fish samples were separated as C, RAT1, and
RAT2, respectively. Following the nano treatment, the minced fish samples were placed into the locked plastic pouch and then stored at $4^{\circ} \mathrm{C}$ for 9 days.

\section{Calibration Process}

The calibration curve of RA was obtained using UVVis Spectrophotometer (Shimadzu, Japan). Standard solutions of RA were prepared to give final concentrations of $1.5625,3.125,6.25,12.5$, and 25 $\mu \mathrm{g} / \mathrm{mL}$. Then the absorbance values of these samples were measured by UV-Vis Spectrophotometer at $324 \mathrm{~nm}$, and the calibration curve was plotted.

\section{Preparation of RA-Loaded PCL-Based Nanoparticles}

The double-emission precipitation method was used to prepare the RA-loaded PCL nanoparticles. $10 \mathrm{mg}$ of RA was dissolved in $1 \mathrm{~mL}$ of distilled water, 30 $\mathrm{mg}$ of PCL was dissolved in dichloromethane, and then the PCL solution was added to the RA solution, respectively. All solutions were mixed and sonicated for 10 minutes using an ultrasonicator at $55 \mathrm{~W}$. This solution was placed into a syringe and then added dropwise into $4 \mathrm{~mL}$ of $5 \%$ PVA solution under continuous stirring. Following these first step procedures, the solution was sonicated again for ten minutes. After that, the mixture was left overnight under continuous stirring in the sonicator. Finally, the obtained RA-loaded nanoparticles were isolated by centrifugation (at 10,000 rpm for $30 \mathrm{~min}$ ). The samples were washed three times to remove the organic solvent and freeze-dried for further characterization analysis and food nanotechnology applications.

\section{Zeta Size (ZS) of Nanoparticles}

The average size distribution of RA-loaded nanoparticles was obtained using a Zeta-Sizer Nano ZS (Malvern Instruments, Malvern, UK) instrument equipped with a $4.0 \mathrm{mV}$ He-Ne laser.

\section{Encapsulation Efficiency}

The loading capacity (LC) and encapsulation efficiency (EE) of RA-loaded PCL nanoparticles were measured by separating the nanoparticles from the aqueous nanoparticle suspension via centrifugation. In this respect, the concentration of free RA in the supernatant was determined using a UV-visible Spectrophotometer via the RA standard curve. The loading capacity and encapsulation efficiency of RAloaded PCL nanoparticles were respectively calculated by the formulas given below. Encapsulated RA amount was calculated by UV-vis absorbance value of supernatant which was obtained after centrifugation of the RA loaded PCL nanoparticles. The UV-vis absorbance value of supernatant put the formula which was obtained from the calibration curve.

$\mathrm{EE}=(($ Total RA Amount-Free RA Amount $) /$ Total RA Amount) $\times 100$ (Eq. 1) 
LC $=$ (Encapsulated RA/Total Nanoparticles Weight) $\times 100 \quad$ (Eq. 2)

\section{The Amount of Released RA}

To determine the in vitro release profile, the release study experiment was conducted at the optimum storage temperature $\left(+4{ }^{\circ} \mathrm{C}\right)$ for meat products. 1 $\mathrm{mg}$ of RA-loaded PCL nanoparticles was dissolved in $2 \mathrm{~mL}$ distilled water and placed in a dialysis capsule. $100 \mathrm{~mL}$ PBS media at $\mathrm{pH}=7.2$ phosphate buffer solution was used as release medium. At designated time intervals, $1 \mathrm{~mL}$ of the release medium was taken and replaced by an equal volume of fresh prewarmed release medium. The amount of released RA in samples was analyzed by UV-Vis spectrometer at $324 \mathrm{~nm}$ wavelength. The amount of $\mathrm{RA}$ released at the end of $144 \mathrm{~h}$ was evaluated from Equation 3, and the \% amount released over time is plotted.

Release Amount (\%) $=$ (Released Amount of $\mathrm{RA}) /($ Total Amount of RA) $\times 100 \quad$ (Eq. 3)

\section{Thermogravimetric Analysis (TGA) of Nano- Scale Material}

Thermal behaviors of PCL nanoparticles and RAloaded PCL nanoparticles were determined using Thermogravimetric Analyzer, TGA (SDT Q600, TA Instruments, and Newcastle, DE USA). As stated by Ceylan, Meral (17) continuous nitrogen flow at a rate of $20 \mathrm{~mL} / \mathrm{min}$ in the temperature range of 25 ${ }^{\circ} \mathrm{C}$ to $800{ }^{\circ} \mathrm{C}$ at a rate of $10^{\circ} \mathrm{C} \mathrm{min}-1$ was applied.

\section{Thiobarbituric Acid (TBA) Analysis}

$10 \mathrm{~g}$ of minced salmon fish samples, $4 \mathrm{~N} \mathrm{HCl}(2.5$ $\mathrm{mL}$ ), and $97.5 \mathrm{~mL}$ of distilled water were added into the flask and then heated for distillation. After the distillation, $5 \mathrm{~mL}$ from the distillate sample was taken and added to the test tubes. All tubes were heated in hot water at $85^{\circ} \mathrm{C}$ for $30 \mathrm{~min}$. Absorbance values of C, RAT1, and RAT2 were measured at 530 $\mathrm{nm}$ using a spectrophotometer (Shimadzu-UV mini 1240, Kyoto-Japon). Finally, TBA results of the samples were calculated as mg malondialdehyde per $\mathrm{kg}$ (mg MDA kg-1) according to Tarladgis, Watts (18).

\section{Antioxidant Activity Measurement by DPPH}

The antioxidant capacity of the minced salmon samples was determined using a modified method as described by Brand-Williams, Cuvelier (19). Salmon fish samples, $5 \mathrm{~g}$ per sample, were mixed with $25 \mathrm{ml}$ of methanol in ice Polytron homogenizer, centrifuged at $7000 \times \mathrm{g}$ for $10 \mathrm{~min}$, and filtered by using Whatman No. 1. The supernatant was mixed with methanol to a volume of $25 \mathrm{~mL}$, and then 50 $\mu \mathrm{L}$ was added to $2950 \mu \mathrm{L}$ of $100 \mu \mathrm{M} \mathrm{DPPH}$ in methanol solution in a test tube. Methanol, $50 \mu \mathrm{L}$, and $2950 \mu \mathrm{L}$ DPPH solution were used to be a blank.
The tubes were covered with parafilm, vortexed, and kept in the dark at room temperature. The absorbance value of the solution was obtained at $517 \mathrm{~nm}$. The standard curve was developed with ascorbic acid and DPPH.

\section{Free Fatty Acid (FFA)}

FFA value as an index of fish fat hydrolyzes was determined according to Egan, Kirk (20). The samples were extracted and then $25 \mathrm{~mL}$ of the extract was mixed with $25 \mathrm{~mL}$ of ethyl alcohol $(95 \%)$. The mixture was titrated against $0.1 \mathrm{~N}$ $\mathrm{NaOH}$ using an indicator (phenolphthalein). The percentages of FFAs in C, RAT1, and RAT2 samples were calculated as oleic acid by using the formula below.

$$
\begin{gathered}
\text { FFA }=((\mathrm{V} \times \mathrm{N} \times 2.82) / \mathrm{W}) \\
\mathrm{V}: \text { Volume of } \mathrm{NaOH} \\
\mathrm{N}: \text { Normality of } \mathrm{NaOH} \\
\mathrm{W}: \text { Weight of Lipid in Extractions }
\end{gathered}
$$

\section{Sensory Evaluation}

Sensory deteriorations in C, RAT1, and RAT2 groups were evaluated by trained sensory panelists as stated by Fan, Sun $(21)(n=10)$. The samples were presented to the trained panelists in a room under well-ventilated and lighted conditions every analysis day. A 10-point hedonic scale was used to evaluate the samples in terms of the overall sensory score (SOVS; obtaining from odor, texture, and color parameters). Score 5.0 was considered as the borderline of all minced fish samples (C, RAT1, and RAT2) acceptability.

\section{Statistical Analysis}

All measurements were repeated twice with three replications. Collected data were subjected to analysis of variance (ANOVA) to evaluate the TBA, DPPH, FFA, and SOVS in all groups. Graphpad Prism software Version 5.00 (California Corporation, CA) was used to reveal significant differences between C, RAT1, and RAT2, and also comparisons of all differences among them were evaluated by the Tukey's Multiple Range Test $(p<0.05)$.

\section{RESULTS AND DISCUSSION}

\section{Particle Distribution of Nanoparticles}

RA solutions were prepared with different concentrations $(1.5625,3.125,6.25,12.5$, and 25 $\mu \mathrm{g} / \mathrm{mL}$ ). Then the absorbance values of these samples were measured by UV-Vis Spectrophotometer at $324 \mathrm{~nm}$, and the calibration curve was plotted (Figure 1).

Zeta Size values of PCL and RAT-loaded PCL nanoparticles were determined to be $213.9 \pm 3.52$ and $235.8 \pm 2.98 \mathrm{~nm}$, respectively Figure $2 \mathrm{~A}$ and $2 \mathrm{~B}$ (Table 1). 


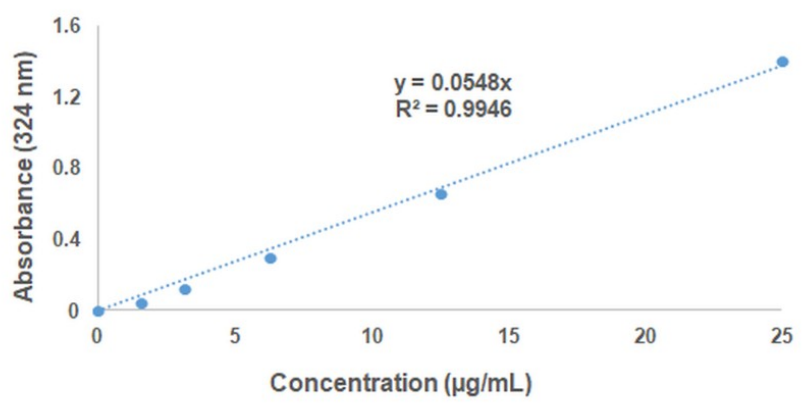

Figure 1: The calibration curve.

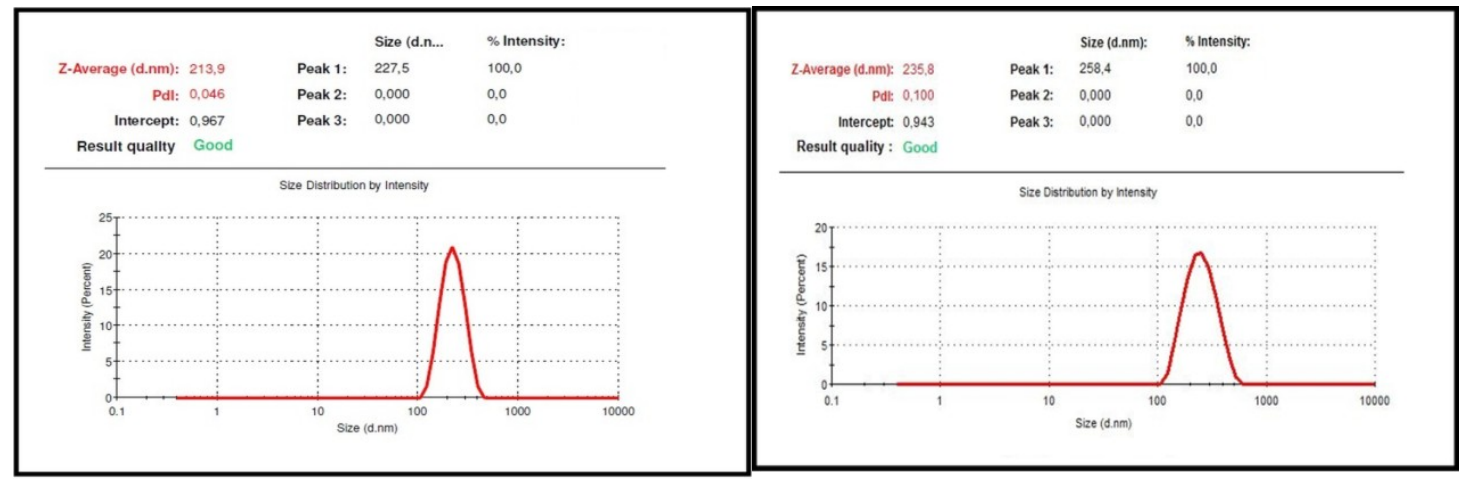

Figure 2: Zeta Size result of (A) blank and (B) RA PCL nanoparticles.

Table 1: Average particle size of nanoparticles.

\begin{tabular}{cc}
\hline Samples & $\begin{array}{c}\text { Average Particle Size } \\
(\mathbf{n m})\end{array}$ \\
\hline PCL NP & $213.9 \pm 3.52$ \\
RAT NP & $235.8 \pm 2.98$ \\
\hline
\end{tabular}

PCL and RAT NPs define poly( $\varepsilon$-caprolactone) and rosmarinic acid-loaded poly( $\varepsilon$-caprolactone), respectively.

The in vitro release study was performed and the release profile graph was drawn based on time and cumulative RA release (\%) (Figure 3) by using calibration curve data of RA. It was determined that RA was released $58.46 \%$ in the first $24 \mathrm{~h}$. Moreover,
93.85\% of RA was released from the RA-loaded PCL nanoparticles end of the 144 th hour. According to the results of in vitro release study, we concluded that the active ingredient (RA) has a controlled manner and slow-release rate over time.

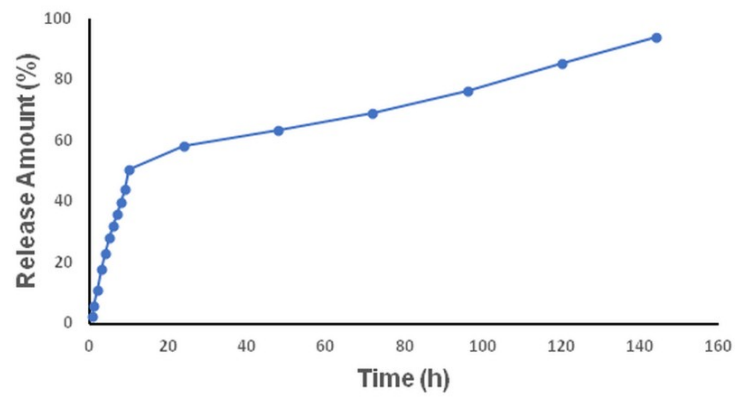

Figure 3: The cumulative RA release. 
Loading of RA into PCL increased the average diameter of the RAT-loaded nanoparticle according to the results of zeta size. Also, the biggest RA- loaded nanoparticle detected by TEM analysis was given in Figure 4.
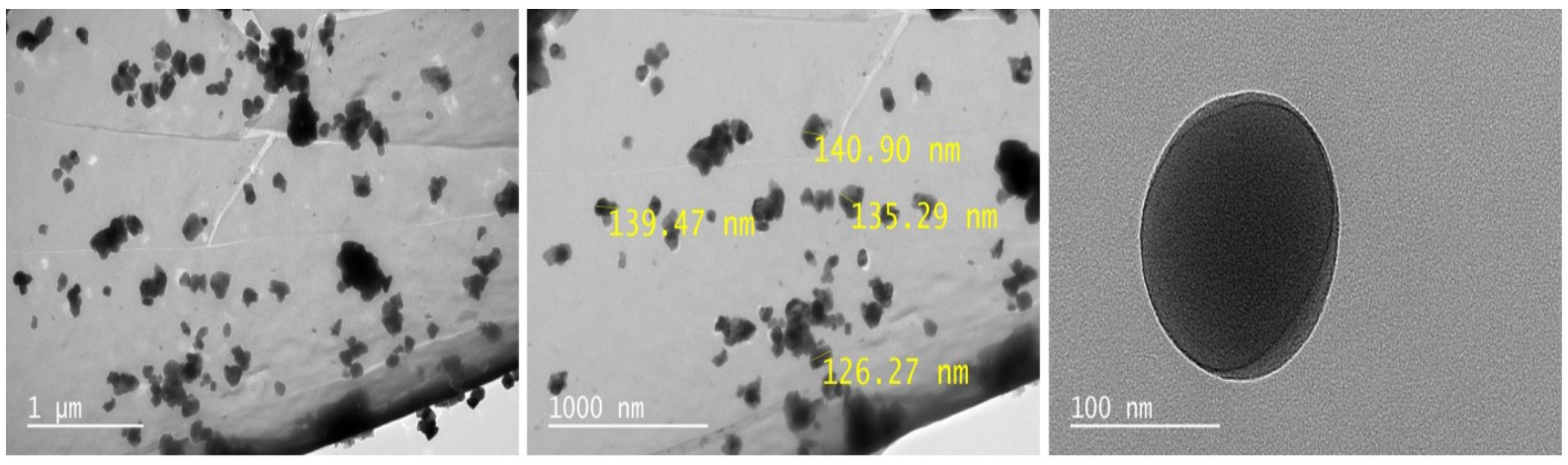

Figure 4: TEM image of RA-loaded nanoparticle.

PCL was used as a nanocarrier in the present study, the antioxidant activity of RA-loaded PCL nanoparticles on the minced salmon samples was revealed. In any nanotechnology application, the diameter of the nanomaterial can play a key role in food applications. Loading of RA into PCL provided an antioxidant effect on the minced salmon samples for 9 days, although RA did not significantly increase the diameter of the nanoparticle $(p<0.05)$. On the other hand, as can be seen from the previous study (8), loading of thymol and liquid smoke into chitosan nanofiber increased the average diameter of the chitosan-based nanofiber. Also, according to Merrell, McLaughlin (22), the diameter of PCL nanofibers fabricated by the electrospinning technique was found to be between 300 and 400 $\mathrm{nm}$. da Silva, Ferreira (23) reported that RA encapsulated chitosan nanoparticles could have a diameter ranging from 200 to $300 \mathrm{~nm}$. In this respect, the loading of RA possessing 235.8 22.98 $\mathrm{nm}$ diameter provided a larger surface area to prevent the rapid oxidation of the minced salmon for 9 days.

\section{Loading Efficiency and Encapsulation of RA- loaded PCL Nanoparticles}

The encapsulation efficiency of the RA was found to be $99.0 \pm 0.35 \%$. This ratio revealed that the RA was highly successfully encapsulated and also effective RA-loaded PCL nanoparticles were obtained. The loading efficiency of the RA-loaded PCL nanoparticles for each $10 \mathrm{mg}$ was found as $9.2 \mathrm{mg}$ of RA. For this study, loading and encapsulation efficiency are important to reveal the effectiveness of RA nanoparticles. Also, the results revealed that the high loading and encapsulation efficiency of RA known as an antioxidant may affect the stability of TBA, DPPH, FFA, and SOVS parameters obtained from the minced salmon samples. In the previous study, Snehalatha, Venugopal (24) reported that encapsulation and loading efficiency of etoposide (into $\mathrm{PCL}$ ) were found to be $80.15 \%$ and $28.8 \%$, respectively. In another study, the loading capacity of RA in chitosan nanoparticles was defined to be lower as compared to our study results (25). As can be also seen from the previous study results, the nanocarrier and loading material play an important role to obtain effective productivity from the nanomaterials.

\section{Thermal Decomposition of the Nanoparticles}

The loss mass of the RA-loaded PCL nanoparticles and PCL nanoparticles was detected by the TGA analysis, as can be seen from Figures 5 and 6 . Cold storage, especially at about $4{ }^{\circ} \mathrm{C}$, is important in the fish processing industry. Therefore, revealing the nanoparticle's thermal decomposition in all mentioned temperature ranges (e.g. $60^{\circ} \mathrm{C}-80^{\circ} \mathrm{C}$, $121^{\circ} \mathrm{C}$ ) is much more important for further food nanotechnology studies as well. In this respect, there was no remarkable mass loss for PCL and RA nanoparticle samples in the range of cold storage temperatures. However, a mass reduction $<0.1328$ $\mathrm{mg}(5.662 \%)$ and $<0.04301 \mathrm{mg}(2.970 \%)$ was recorded respectively for $\mathrm{PCL}$ and $\mathrm{RA}$ nanoparticle samples at about in the range of 65 and $80^{\circ} \mathrm{C}$. As compared to $80^{\circ} \mathrm{C}$, there was no remarkable mass reduction for both nanoparticle samples at $121^{\circ} \mathrm{C}$.

Thermal decomposition started at $250{ }^{\circ} \mathrm{C}$ for $\mathrm{PCL}$ nanoparticles with above $15 \%$, but at the same temperature, loss in mass was found about $8.5 \%$ for the RA nanoparticles. Previous study results indicated that the type of the used material (probiotic bacteria or polymer etc.) play an important role to determine the thermal behavior of the nanoparticles. Ceylan, Meral (17) defined that the lost weight in nanofibers obtained from $L$. rhamnosus was found to be $\geq 5 \%$ up to $200{ }^{\circ} \mathrm{C}$ degrees. However, Zhao, Li (26) reported that thermal decomposition of chitosan-based nanofibers started at $240^{\circ} \mathrm{C}$ and was completed at $650{ }^{\circ} \mathrm{C}$. Therefore, the thermal behavior of obtained nanomaterials should be revealed for further studies related to food nanotechnology. 


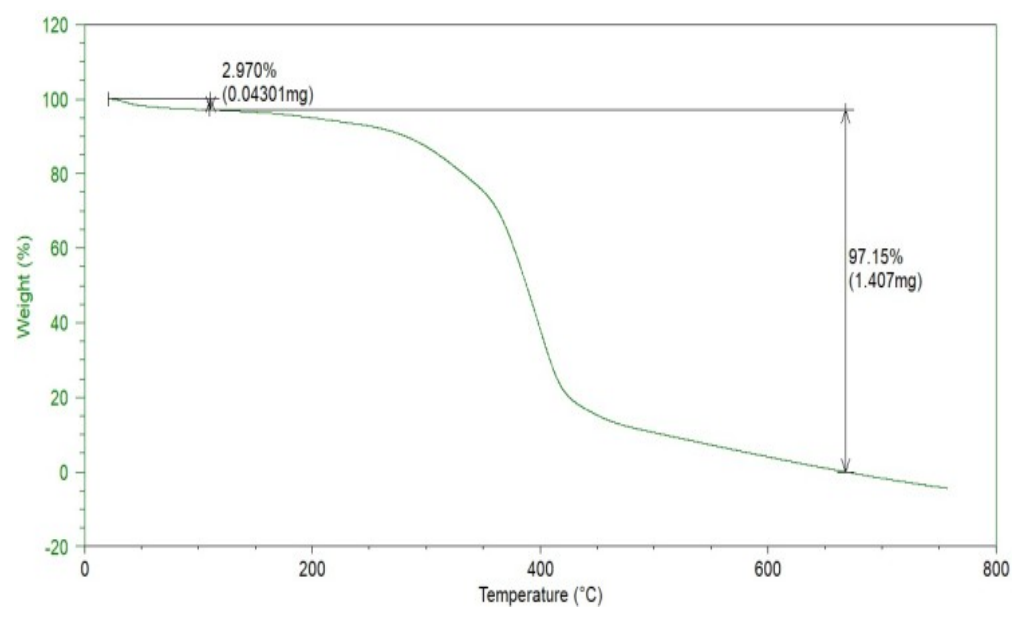

Figure 5: Thermal decomposition of rosmarinic acid-loaded PCL-based nanoparticles.

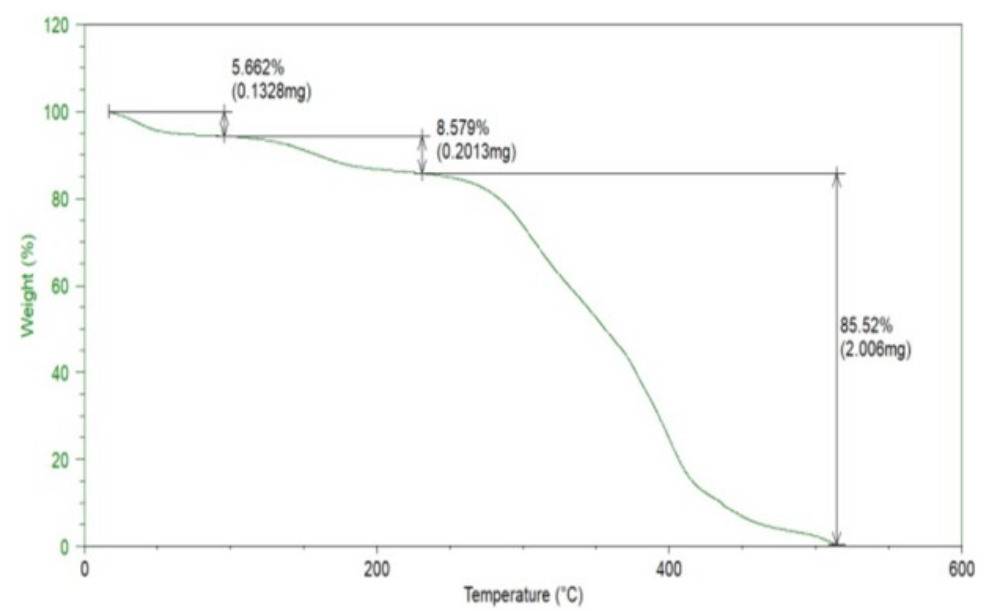

Figure 6: Thermal decomposition of PCL nanoparticles.

The Role of RA Nanoparticles in Lipid Oxidation and Antioxidant Activity (TBA)

The TBA results of processed and untreated minced salmon samples are given in Table 2. The TBA values of untreated minced salmon were higher than those of RA nanoparticles with different ratios $(p<0.05)$. While the TBA value of untreated samples was measured to be $0.51 \mathrm{mg} \mathrm{MDA} \mathrm{kg}^{-1}$ fish meat on the first day of the cold storage period, TBA values of RAT1 and RAT2 were found to be 0.18 and 0.155 mg MDA kg-1, respectively. In another word, as compared to the control group samples, the increase in TBA of RAT1 and RAT2 samples was limited by 64.7 and $69.6 \%$, respectively. As stated by Khalafalla, Ali (27), TBA value is evaluated to be an indicator of secondary lipid oxidation products. Therefore, in terms of revealing the lipid oxidation in fish products, it could play a key role. TBA value in fish samples, depending on the increase in storage period, can increase. With the increase of the storage period, the TBA level in C samples rapidly has increased as compared to the samples treated with nanomaterials (RAT1 and RAT2). In this respect, on the $5^{\text {th }}$ day of the cold storage, TBA values of C, RAT1, and RAT2 samples were defined as $1.12,0.4$ (64.28\% decrease), and $0.175 \mathrm{mg}$ MDA $\mathrm{kg}^{-1}(84.37 \%$ decrease), respectively $(p<0.05)$. At the end of the cold storage period, the TBA value of C samples reached $2.995 \mathrm{mg} \mathrm{MDA} \mathrm{kg}{ }^{-1}$ when the TBA values of RAT1 and RAT2 samples could reach

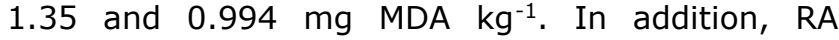
nanoparticles treatments have provided the limitation in the range of $54.92 \%$ and $84.37 \%$ for 9 days $(p<0.05)$. Roomiani, Ghaeni $(28)$ reported that rosemary essential oils at $0.2 \%$ and $0.4 \%$ were effective in controlling lipids of fish fillets stored at $18^{\circ} \mathrm{C}$ for 6 months. Li, Mei (29) reported that the treatment of $1 \%$ chitosan coating incorporated with 20,30 , or $40 \mathrm{mg} / \mathrm{L}$ RA to delay the increase in TBA value of rainbow trout samples was successfully applied. When compared to the previous literature studies, it is seen that nanotechnology applications with $8.10^{-3} \mathrm{~g}$ and $16.10^{-3} \mathrm{~g}$ provided a big advantage to limit the rapid increase in the TBA value of minced fish products. Because nanomaterials could provide a larger contact area as compared to 
microsized materials (5) and they can more successfully limit the penetration of oxygen that may cause the oxidation in fatty fish.

There is a linear correlation between the total phenolic substance amount and total antioxidant, which can be defined by the DPPH method (30). DPPH is one of the organic nitrogen radicals, also RA has phenolic compounds and fish meat has nitrogen, therefore some phenolic compounds could react with DPPH radicals. The amino acid composition, the abundance of free amino acids, peptide size, and solubility may have a key role in defining the DPPH radical scavenging capacity (31-34). The results of the DPPH (\%) analysis are presented in Table 2. According to these results, the DPPH values of control group samples ranged from $1.184 \%$ to $1.669 \%$. On the other hand, the DPPH values of the minced fish treated with RA nanoparticles rapidly increased as compared to those of the control group samples. On the $1^{\text {st }}$ day of the cold storage, the DPPH value of RAT1 samples $(2.843 \%)$ was found to be lower than those of the minced salmon samples treated with RAT2 samples $(3.757 \%) \quad(p<0.05)$. Depending on the increase of the storage period, DPPH values of RAT1 and RAT2 samples highly increased because the release profile of RA may begin to increase as can be seen from Figure 2 . During the storage period, the DPPH value in $C$ samples can increase because of nitrogen compounds, peptide structure in fish meat. However, DPPH values of RAT1 and RAT2 samples can more rapidly increase because they may have an interaction between the phenolic compound and nitrogen compounds in fish meat. Ceylan, Uslu (35) reported that the DPPH activity of the rainbow trout fillets treated with nanoencapsulated $L$. reuteri significantly was increased (up to $100 \%$ ). Similarly, $\mathrm{Hu}$, Wang (36), and Badawy, Lotfy (37) indicated that chitosan nanoparticles showed an excellent antioxidant effect for the meat samples during refrigerated storage. They also reported that the antioxidant activity significantly reduced with the storage time increase. Morsy, Mekawi (38) claimed that lyophilized pomegranate peel nanoparticles had a high phenolic content and antioxidant capacity. Meral and Köse (39) revealed that there is a good relationship between the total phenolic compounds and antioxidant activity in foods. Moreover, Meral (40) noted that antioxidant activity may be affected by different factors such as food composition, the amount of the food components, the interaction of food components, and technological processes.

Table 2: Oxidation parameters, antioxidant activity, and sensory analysis results of the minced salmon samples treated with nanoparticles and untreated samples.

\begin{tabular}{ccccc}
\hline & & & Groups & RAT2 \\
\hline Storage days & Parameters & C & RAT1 & $0.155 \pm 0.000^{\mathrm{C}}$ \\
& TBA & $0.510 \pm 0.000^{\mathrm{A}}$ & $0.180 \pm 0.000^{\mathrm{B}}$ & $3.757 \pm 0.430^{\mathrm{A}}$ \\
& DPPH & $1.184 \pm 0.335^{\mathrm{C}}$ & $2.843 \pm 0.191^{\mathrm{B}}$ & $0.964 \pm 0.023^{\mathrm{C}}$ \\
& FFA & $2.011 \pm 0.020^{\mathrm{A}}$ & $1.399 \pm 0.014^{\mathrm{B}}$ & $8.650 \pm 1.032^{\mathrm{A}}$ \\
\hline & SOVS & $9.666 \pm 0.516^{\mathrm{A}}$ & $9.165 \pm 0.752^{\mathrm{A}}$ & $0.175 \pm 0.000^{\mathrm{C}}$ \\
& TBA & $1.120 \pm 0.009^{\mathrm{A}}$ & $0.400 \pm 0.019^{\mathrm{B}}$ & $3.568 \pm 0.170^{\mathrm{A}}$ \\
& DPPH & $1.202 \pm 0.680^{\mathrm{C}}$ & $2.646 \pm 0.113^{\mathrm{B}}$ & $2.101 \pm 0.072^{\mathrm{A}}$ \\
& FFA & $2.507 \pm 0.205^{\mathrm{A}}$ & $2.029 \pm 0.405^{\mathrm{A}}$ & $7.600 \pm 0.547^{\mathrm{A}}$ \\
\hline & SOVS & $4.660 \pm 0.816^{\mathrm{C}}$ & $7.500 \pm 0.547^{\mathrm{B}}$ & $0.994 \pm 0.004^{\mathrm{C}}$ \\
& TBA & $2.995 \pm 0.064^{\mathrm{A}}$ & $1.350 \pm 0.044^{\mathrm{B}}$ & $7.112 \pm 0.443^{\mathrm{A}}$ \\
& DPPH & $1.669 \pm 1.331^{\mathrm{C}}$ & $5.282 \pm 0.073^{\mathrm{B}}$ & $2.494 \pm 0.153^{\mathrm{C}}$ \\
& FFA & $4.338 \pm 0.390^{\mathrm{A}}$ & $2.765 \pm 0.076^{\mathrm{B}}$ & $2.833 \pm 0.410^{\mathrm{A}}$ \\
\hline
\end{tabular}

A-C Within each row, different superscript lowercase letters show differences between treatment groups for the same analysis group $(p<0.05)$. C: Minced salmon fish samples untreated, RAT1 and RAT2: Salmon fish samples treated with $8.10^{-3} \mathrm{~g}$ and $16.10^{-3} \mathrm{~g}$ RA nanoparticles, respectively. TBA: mg MDA $\mathrm{kg}^{-1}, \mathrm{DPPH}: \%$, FFA: \%

\section{The Effect of RA Nanoparticles in Free Fatty Acid Levels (FFA)}

The results of the FFA analysis are indicated in Table 2 . The FFA values in the minced salmon samples ( $C$, RAT1, and RAT2) increased with storage time. The FFA values of $C$ group samples were found to be higher when compared with those of RAT1 and RAT2 samples. Also, for 9 days, the FFA value of the minced salmon fish samples treated with RAT2 nanoparticles was determined to be lower than that of RAT1 samples. During 9 days, there were also statistical differences among all groups $(p<0.05)$. 
Moreover, the initial FFA value of $\mathrm{C}$ samples was $2.011 \%$, but at the end of the cold storage, this value reached $4.338 \%$ while FFA values of RAT1 and RAT2 samples were found to be $2.765 \%$ and $2.494 \%$, respectively. A high-level FFA value can be defined by an undesirable aroma. Fish oil contains a great deal of PUFAs that can easily lead to the initiation of oxidation reactions and the formation of hydroperoxides of fatty acids. Also, bacterial activity plays a key role in the increase of FFA value in fish meat $(41,42)$. In addition, FFA values are used as a quality indicator of fish oils (43). Bimbo (44) reported that the FFA values of food-grade fish oil were found to be higher at the end of nine days of storage. The recommended FFA value is determined in the range of 1 and $7 \%$. In this respect, as can be seen from the results of the study, nano-application in the present study provided a higher quality for minced salmon samples at $4{ }^{\circ} \mathrm{C}$. In this respect, rosmarinic nanoparticle applications $\left(8.10^{-3}\right.$ and $16.10^{-3} \mathrm{~g}$ ) with a larger contact area property successfully limited the rapid increase in the FFA value of fish meat.

\section{The Role of RA Nanoparticles in Sensory Quality}

Overall sensory scores of the minced salmon fish samples treated with RA nanoparticles, and without RA nanoparticles samples are shown in Table 2. Once the sensory score of all samples reached the point of minimum acceptability (5) grades, the samples were evaluated to be unfit for human consumption. All sensory attributes of every sample showed a declining trend for 9 days. After 5 days of refrigerated storage, putrid and fishy odor in untreated (C) samples was determined. On the 5th day of the refrigerated storage period, the FFA value of $C$ samples reached 2.507 , but, on the 9th day of the refrigerated storage, RAT2 samples could be measured as 2.494. The sensory quality of the samples treated with $8.10^{-3}$ and $16.10^{-3} \mathrm{~g}$ RA nanoparticles delayed the oxidation by four days when compared to the control samples. Tsai, Su (45) defined that the shelf life of salmon loins that were dipped into chitosan solution (1\%) could be prolonged by four days as compared to control group samples stored at $4{ }^{\circ} \mathrm{C}$. When compared to the amount of the used substance, in the present study better quality was provided with highly less nanomaterial.

\section{CONCLUSION}

The RA-loaded PCL nanoparticles were obtained with $235.8 \pm 2.98 \mathrm{~nm}$ average particle size. The oxidation in the minced salmon fish samples was effectively limited using RA-loaded PCL nanoparticles for 9 days under cold storage conditions. The rapid changes in TBA, FFA values, and overall sensory score were limited although DPPH values of the minced salmon samples increased with time. Per $100 \mathrm{~g}$ minced salmon fish sample, especially, the use of $8.10^{-3}$ and $16.10^{-3} \mathrm{~g}$ nanoform of RA provided well preservation for the limitation of the rapid increase in the tested oxidation parameters. It was revealed that the high loading and encapsulation efficiency of RA, in this respect especially RAT2 application, had an important effect on the oxidative stability of minced salmon samples. The nanoapplication presented a larger contact area on the surface of the minced fish. In this sense, the present study revealed that the use of RA in a nanotechnology application could be a promising approach, especially for fatty and minced food products.

\section{CONFLICT OF INTEREST}

Authors have no conflict of interest.

\section{REFERENCES}

1. Thilsted S, James D, Toppe J, Subasinghe R, Karunasagar I. Maximizing the contribution of fish to human nutrition. In FAO; 2014. $\leq$ URL>.

2. Altan CO, Turan H. Synergistic Effect of Freezing and Irradiation on Bonito Fish (Sarda sarda Bloch, 1793). Journal of Food Protection. 2016 Dec 1;79(12):2136-42. $\leq \mathrm{DOI}>$.

3. Das $P$, Ganguly S. Chilling and freezing techniques for fish presrvvation and maintenance of quality parameters: A Review. Ind J Sci Res and Tech. 2014;2(6):3-5.

4. Khanipour A, Mirzakhani N. Effect of different packaging methods on shelf life of hot smoked rainbow trout (Oncorhynchus mykiss) during storage at $0-2^{\circ} \mathrm{C}$. Iranian Journal of Fisheries Science. 2013;12(3):620-8. $\leq$ URL $>$.

5. Ceylan Z, Sengor GFU, Yilmaz MT. A Novel Approach to Limit Chemical Deterioration of Gilthead Sea Bream (Sparus aurata) Fillets: Coating with Electrospun Nanofibers as Characterized by Molecular, Thermal, and Microstructural Properties: Coating with electrospun nanofiber... Journal of Food Science. 2017 May;82(5):1163-70. <DOI $>$.

6. Özogul Y, Durmus M, Ucar Y, Özogul F, Regenstein JM. Comparative study of nanoemulsions based on commercial oils (sunflower, canola, corn, olive, soybean, and hazelnut oils): Effect on microbial, sensory, and chemical qualities of refrigerated farmed sea bass. Innovative Food Science \& Emerging Technologies. 2016 Feb;33:422-30. <DOI $>$.

7. Osheba A, Sorour M, Abdou E. Effect of chitosan nanoparticles as active coating on chemical quality and oil uptake of fish fingers. Journal of Agriculture and Environmental Sciences. 2013;2(1):1-14.

8. Ceylan $Z$, Unal Sengor GF, Yilmaz MT. Nanoencapsulation of liquid smoke/thymol combination in chitosan nanofibers to delay microbiological spoilage of sea bass ( Dicentrarchus labrax ) fillets. Journal of Food Engineering. 2018 Jul;229:43-9. $\leq$ DOI $>$.

9. Oner B, Meral R, Ceylan Z. Determination of some quality indices of rainbow trout fillets treated with nisinloaded polyvinylalcohol-based nanofiber and packed with 
polyethylene package. LWT. 2021 Sep;149:111854. $\leq \mathrm{DOI}$.

10. Yao Z-C, Chang M-W, Ahmad Z, Li J-S. Encapsulation of rose hip seed oil into fibrous zein films for ambient and on demand food preservation via coaxial electrospinning. Journal of Food Engineering. 2016 Dec;191:115-23. $<$ DOI $>$.

11. Fabra MJ, López-Rubio A, Lagaron JM. Use of the electrohydrodynamic process to develop active/bioactive bilayer films for food packaging applications. Food Hydrocolloids. 2016 Apr;55:11-8. <DOI.

12. Castro-Mayorga JL, Fabra MJ, Pourrahimi AM, Olsson RT, Lagaron JM. The impact of zinc oxide particle morphology as an antimicrobial and when incorporated in poly(3-hydroxybutyrate-co-3-hydroxyvalerate) films for food packaging and food contact surfaces applications. Food and Bioproducts Processing. 2017 Jan;101:32-44. $\leq \mathrm{DOI}>$.

13. Meral R, Alav A, Karakas C, Dertli E, Yilmaz MT, Ceylan $Z$. Effect of electrospun nisin and curcumin loaded nanomats on the microbial quality, hardness and sensory characteristics of rainbow trout fillet. LWT. 2019 Oct;113:108292. <DOI $>$.

14. Kutlu N, Meral R, Ekin MM, Erim Kose Y, Ceylan Z. A new application for the valorisation of pomegranate seed oil: nanoencapsulation of pomegranate seed oil into electrospun nanomats for food preservation. Int $\mathrm{J}$ of Food

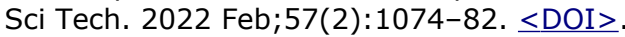

15. Ceylan Z, Kutlu N, Meral R, Ekin MM, Kose YE. Protective effect of grape seed oil-loaded nanofibers: Limitation of microbial growth and lipid oxidation in kashar cheese and fish meat samples. Food Bioscience. 2021 Aug;42:101076. <DOI $>$.

16. Cetinkaya T, Wijaya W, Altay F, Ceylan Z. Fabrication and characterization of zein nanofibers integrated with gold nanospheres. LWT. 2022 Feb;155:112976. <DOI .

17. Ceylan Z, Meral R, Karakaş CY, Dertli E, Yilmaz MT. A novel strategy for probiotic bacteria: Ensuring microbial stability of fish fillets using characterized probiotic bacteria-loaded nanofibers. Innovative Food Science \& Emerging Technologies. 2018 Aug;48:212-8. <DOI>.

18. Tarladgis BG, Watts BM, Younathan MT, Dugan L. A distillation method for the quantitative determination of malonaldehyde in rancid foods. J Am Oil Chem Soc. 1960 Jan;37(1):44-8. $\leq$ DOI $>$.

19. Brand-Williams W, Cuvelier ME, Berset C. Use of a free radical method to evaluate antioxidant activity. LWT - Food Science and Technology. 1995;28(1):25-30. <DOI >.

20. Egan H, Kirk R, Sawyer R, editors. Pearson's Chemical Analysis of Food. In: 8th edition. Sussex, UK: Langnan Scientific and Technical; 1987.

21. Fan W, Sun J, Chen Y, Qiu J, Zhang Y, Chi Y. Effects of chitosan coating on quality and shelf life of silver carp during frozen storage. Food Chemistry. 2009 Jul;115(1):66-70. <DOI>.

22. Merrell JG, McLaughlin SW, Tie L, Laurencin CT, Chen AF, Nair LS. Curcumin-loaded poly( $\varepsilon$-caprolactone) nanofibres: Diabetic wound dressing with anti-oxidant and anti-inflammatory properties. Clinical and Experimental Pharmacology and Physiology. 2009 Dec;36(12):1149-56. $\leq \mathrm{DOI}>$.

23. da Silva SB, Ferreira D, Pintado M, Sarmento B. Chitosan-based nanoparticles for rosmarinic acid ocular delivery-In vitro tests. International Journal of Biological Macromolecules. 2016 Mar;84:112-20. <DOI .

24. Snehalatha M, Venugopal K, Saha RN. EtoposideLoaded PLGA and PCL Nanoparticles I: Preparation and Effect of Formulation Variables. Drug Delivery. 2008 Jan;15(5):267-75. <DOI $>$.

25. Darwish Y, Abd-Elhakeem M, El-Maksod A, Sabit H, ElZawahri M. Antitumor Activity of Rosmarinic Acid Encapsulated in Chitosan Nanoparticles. Acad J Cancer Res. 2018;11:1-8.

26. Zhao R, Li X, Sun B, Zhang Y, Zhang D, Tang Z, et al. Electrospun chitosan/sericin composite nanofibers with antibacterial property as potential wound dressings. International Journal of Biological Macromolecules. 2014 Jul; 68:92-7. $\leq$ DOI $>$.

27. Khalafalla FA, Ali FHM, Hassan A-RHA. Quality improvement and shelf-life extension of refrigerated Nile tilapia (Oreochromis niloticus) fillets using natural herbs. Beni-Suef University Journal of Basic and Applied Sciences. 2015 Mar;4(1):33-40. <DOI $>$.

28. Roomiani L, Ghaeni M, Moarref M, Fallahi R, Lakzaie F. The effects of Rosmarinus officinalis essential oil on the quality changes and fatty acids of Ctenopharyngodon idella. Iranian Journal of Fisheries Sciences [Internet]. $2018 \leq$ DOI $>$

29. Li N, Mei J, Shen Y, Xie J. Quality improvement of halfsmooth tongue sole ( Cynoglossus Semilaevis ) fillets by chitosan coatings containing rosmarinic acid during storage. CyTA - Journal of Food. 2018 Jan;16(1):1018-29. $\leq \mathrm{DOI}>$.

30. Huang $D$, Ou B, Prior RL. The Chemistry behind Antioxidant Capacity Assays. J Agric Food Chem. 2005 Mar $1 ; 53(6): 1841-56$. $\leq$ DOI $>$.

31. Ndhlala A, Moyo M, Van Staden J. Natural Antioxidants: Fascinating or Mythical Biomolecules? Molecules. 2010 Oct 8;15(10):6905-30. <DOI $>$.

32. Ryan JT, Ross RP, Bolton D, Fitzgerald GF, Stanton C. Bioactive Peptides from Muscle Sources: Meat and Fish. Nutrients. 2011 Aug 31;3(9):765-91. <DOI>.

33. Samadi B, Ismail A. Antioxidative peptides from food Peptides Review. Peptides. 2010;31(10):1949-56.

34. Samaranayaka AGP, Li-Chan ECY. Food-derived peptidic antioxidants: A review of their production, assessment, and potential applications. Journal of Functional Foods. 2011 Oct;3(4):229-54. <DOI $>$.

35. Ceylan Z, Uslu E, İspirli H, Meral R, Gavgalı M, 'Yilmaz $M T$, et al. A novel perspective for Lactobacillus reuteri: Nanoencapsulation to obtain functional fish fillets. LWT. 2019 Nov; 115:108427. <DOI $>$. 
36. Hu J, Wang X, Xiao Z, Bi W. Effect of chitosan nanoparticles loaded with cinnamon essential oil on the quality of chilled pork. LWT - Food Science and Technology. 2015 Sep;63(1):519-26. <DOI>.

37. Badawy MEI, Lotfy TMR, Shawir SMS. Facile synthesis and characterizations of antibacterial and antioxidant of chitosan monoterpene nanoparticles and their applications in preserving minced meat. International Journal of Biological Macromolecules. 2020 Aug;156:127-36. $<$ DOI $>$.

38. Morsy MK, Mekawi E, Elsabagh R. Impact of pomegranate peel nanoparticles on quality attributes of meatballs during refrigerated storage. LWT. 2018 Mar;89:489-95. <DOI $>$.

39. Meral R, Köse YE. The effect of bread-making process on the antioxidant activity and phenolic profile of enriched breads. Quality Assurance and Safety of Crops \& Foods. 2019 Apr 9;11(2):171-81. <DOI>.

40. Meral R. The effect of different temperatures on antioxidant activity and phenolic profile of the Rheum ribes. YYU Journal of Agricultural Science. 2017;27:88-94.
41. Ježek F, Buchtová H. Monitoring of Physicochemical Changes in Frozen Fish Muscle Tissue. Agriculturae Conspectus Scientificus. 2011;76(3):201-4. $\leq$ URL $>$.

42. Milijašević $M$, Milijašević JB, Djinović-Stojanović J, Moračanin SV, Lilić S. Changes of $\mathrm{pH}$ and peroxide value in carp (Cyprinus carpio) cuts packaged in modified atmosphere. IOP Conference Series: Earth and Environmental Science. 2017 Sep;85:012041. <DOI>.

43. Wu TH, Bechtel PJ. Salmon by-product storage and oil extraction. Food Chemistry. 2008 Dec 15;111(4):868-71. $<$ DOI $>$.

44. Bimbo AP. Guidelines for characterizing food-grade fish oils. Inform [Internet]. 1998;9(5). Available from: $\leq U R L>$.

45. Tsai G-J, Su W-H, Chen H-C, Pan C-L. Antimicrobial activity of shrimp chitin and chitosan from different treatments and applications of fish preservation. Fisheries Sci. 2002 Feb;68(1):170-7. <DOI 2. 